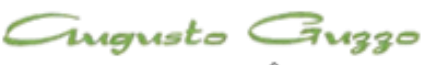

REVISTA ACADEMICA

\title{
Planejamento tributário para clientes de escritório de contabilidade
}

\author{
Gláucia Regina Torres ${ }^{1}$ e Danielle Ribeiro de Freitas Castro² \\ Recebido em: 03/10/2013. Aprovado em: 16/11/2013. Disponibilizado em: 20/12/2013 \\ 1. Gláucia Regina Torres, Especialista em Controladoria da Fundação Escola de Comércio Álvares Penteado - FECAP. \\ 2. Orientadora profa Ms Danielle Ribeiro de Freitas Castro.
}

\section{Resumo}

O objetivo desta pesquisa é desenvolver uma breve contextualização sobre à empresa prestadora de serviço, tributada pelo lucro presumido ou lucro real, e fazer um comparativo entre as tributações, para verificar qual tributação aplicada numa empresa prestadora de serviço que tem específicamente receita de juros sobre capital próprio e lucro do exercício, obtém uma economia fiscal focada no imposto de renda e contribuição social. Através de um bom planejamento tributário, visando promover a difusão de procedimentos amparados por lei, e que venham auxiliar os profissionais a ampliar suas possibilidades de redução no recolhimento dos impostos, o que poderá refletir positivamente nos resultados da empresa. Este artigo irá demonstrar e comparar os benéficios que um correto enquadramento no regime tributário e sua forma de tributação pode representar no resultado da empresa e dizer se a empresa obteve uma elisão fiscal ou evasão fiscal. Através de informações teóricas confiáveis e finalmente com um modelo aplicado em uma situação real, o que irá nos garantir uma visão do todo, objetivando assim possibilidades perfeitamente aplicáveis e que nos darão os benefícios oferecidos pela tributação do lucro presumido ou lucro real.

Palavras-chave: Planejamento tributário. Lucro presumido. Lucro real. Economia fiscal.

\begin{abstract}
The aim of this work is to develop a brief contextualization on the service provider company taxed on estimated profit or taxable income, and make a comparison between the taxation applied to determine which tax applied on a service provider company that has specifically income interest on equity and profit for the year, obtain a tax economy focused on income tax and social contribution. Through a good tax planning, to promote the diffusion of procedures supported by law, that will help professionals increase their chances of reduction in payment of taxes, which may reflect positively on company results. This article will demonstrate and compare the benefits that a proper framework in the tax regime and its form of taxation may represent in the company's result and to say if the company had a tax avoidance or tax evasion. Through reliable theoretical information and finally with a model applied in a real situation, it will give
\end{abstract}


us a vision of the whole, thus aiming so perfectly applicable possibilities that will give us the benefits offered by the taxation of estimated income or taxable income.

Keywords: Tax planning. Presumed profit. Taxable income. tax savings

TORRES, G.R. e CASTRO, D.R.F.: Planejamento tributário para clientes de escritório de 


\section{Introdução}

A decisão de escrever este artigo está, basicamente, correlacionada à alta carga tributária do Brasil, que é um dos maiores impasse para o desenvolvimento da economia e das empresas. Dependendo da forma de tributação que adotar tem que desembolsar uma boa parte de receitas de sua atividade. Esta pesquisa possui o objetivo de estudar se a adoção de um planejamento tributário, especificamente do imposto de renda e da contribuição social para empresa tributada pelo lucro presumido e lucro real contribui para a economia tributária. E objetivamente efetuar um comparativo no planejamento tributário adotado por uma empresa do ramo de prestação de serviços.

O estudo da definição dos tributos, seu destino e sua distribuição são essenciais para sua compreensão e finalidade e conseqüentemente, pode trazer ao empresário uma visão de suas obrigações e a possibilidade da redução da carga tributária. Com a exaustiva carga tributária no Brasil, tornou-se necessário por parte dos donos de escritório de contabilidade estar preparado em oferecer um planejamento tributário, para proporcionar ao seu cliente a maneira mais vantajosa de recolhimento dos tributos buscando uma economia fiscal.

A investigação tem a intenção de responder a seguinte questão: $\mathrm{O}$ planejamento tributário do imposto de renda contribui para a economia fiscal de uma empresa?

$\mathrm{O}$ artigo se justifica, ao trazer para os escritórios de contabilidade, que também prestam serviços de planejamento tributário, um comparativo entre duas formas de apuração de tributos, demonstrando assim a melhor forma de tributação que uma empresa deve adotar para garantir uma economia fiscal.
A hipótese que esta pesquisa tem a intenção de confirmar é que um planejamento tributário corretamente desenvolvido traz sim uma economia fiscal, desde que sejam levadas em conta todas as particularidades do ramo de atividade da empresa objeto do planejamento tributário.

\section{Referencial Teórico}

\subsection{Planejamento Tributário}

Planejamento Tributário, é o conjunto de sistemas legais que visam diminuir o pagamento de tributos, estruturando seu negócio da melhor maneira que pareça, objetivando a diminuição dos custos de seu empreendimento, inclusive dos impostos, de forma celebrada é jurídica e lícita. Nunca deve ser confundido como ocultar a fiscalização da lei. Planejar e fazer escolhas entre as opções lícitas, aquela que possa dar melhores resultados para a empresa.

Código Tributário Nacional art.3, Tributo é toda prestação pecuniária compulsória, em moeda ou cujo valor nela se possa exprimir, que não constitua sanção de ato ilícito, instituída em lei e cobrada mediante atividade administrativa plenamente vinculada.

\subsection{Formas de Tributação}

Na prática, são quatro as modalidade de tributação pelo IRPJ (Imposto Renda Pessoa Jurídica): Lucro Real, Lucro Presumido, Lucro Arbitrado e Simples Nacional.

\subsubsection{Lucro Presumido}

O Lucro presumido pode se dizer que é uma forma simplificada de apurar o IRPJ, porque se dá pela presunção do lucro, e elegendo a opção pelo lucro presumido no ato do pagamento da primeira ou única quota.

O $\int 1^{\circ}$ do art.13 da Lei $n^{\circ} 9.718 / 98$ dispõe que a opção pela tributação com 
base no lucro presumido será definitiva em relação a todo o ano calendário, Com isso, está revogada a faculdade prevista no art. $26 \int 3^{\circ}$, da Lei $n^{\circ}$ 9.430/96 para mudar a opção de lucro presumido para real trimestral ou anual, no curso do ano calendário ou por ocasião da entrega da declaração de informações.

A tabela I se refere às alíquotas tributadas pelo lucro presumido, aplicada a empresa do ramo prestadora de serviço, comercio e indústria.

Tabela I - Alíquota para Tributação Lucro Presumido

\begin{tabular}{|l|c|c|c|}
\hline TRIBUTO & SERVIÇO & COMERCIO & INDUSTRIA \\
\hline PIS & $0,65 \%$ & $0,65 \%$ & $0,65 \%$ \\
\hline COFINS & $3,00 \%$ & $3,00 \%$ & $3,00 \%$ \\
\hline CSLL & $32 \% / 9 \%$ & $16 \% / 9 \%$ & $8 \% / 9 \%$ \\
\hline IRPJ & $32 \% / 15 \%$ & $16 \% / 15 \%$ & $8 \% / 15 \%$ \\
\hline
\end{tabular}

Fonte: Tabela preparada pela autora em 6/2014.

\subsubsection{Lucro Real}

É primordial que a pessoa jurídica tributada com base no lucro real mantenha escrituração comercial regular (contabilidade), além, é claro do livro de apuração do Lucro Real (LALUR). Estão obrigadas ao regime de tributação com base no lucro real, em cada ano calendário, as pessoas jurídicas:

De acordo com Santos, Barros (2010), a) cuja receita total, no ano calendário anterior, tenha sido superior ao limite de $\mathrm{R} \$$ 48.000.000,00 ou proporcional ao número de meses do período, quando inferior a 12 meses, b) cujas atividades sejam de bancos comerciais, bancos de investimentos, bancos de desenvolvimento, caixas econômicas, sociedade de crédito, financiamento e investimentos, sociedades de crédito mobiliário e câmbio, distribuidoras de títulos e valores mobiliários, empresas de arrendamento mercantil, cooperativas de crédito, empresas de seguros privados e de capitalização e entidades de previdência privada aberta, c) que tenham lucros, rendimentos ou ganhos de capital oriundo do exterior, d) que, autorizadas pela legislação tributária, usufruam de benefícios fiscais relativos à isenção ou redução do imposto, e) que, no decorrer do ano- calendário, efetuem pagamento mensal do imposto de renda pelo regime de estimativa, f) que explorem as atividades de prestação cumulativa e contínua de serviços de assessoria creditícia, mercadológica, gestão de crédito, seleção e riscos, administração de contas a pagar e a receber, compras de direitos creditórios resultantes de vendas mercantis a prazo ou de prestação de serviços (factoring), g) constituída como Sociedade de Propósito Específico formada por microempresa e empresa de pequeno porte optante pelo Simples Nacional.

A tabela II se refere às alíquotas tributadas pelo lucro real, aplicada a empresa do ramo prestadora de serviço, comercio e indústria. 
Tabela II - Alíquota para Tributação Lucro Real

\begin{tabular}{|l|c|c|c|}
\hline TRIBUTO & SERVIÇO & COMERCIO & INDUSTRIA \\
\hline PIS & $1,65 \%$ & $1,65 \%$ & $7,65 \%$ \\
\hline COFINS & $7,60 \%$ & $7,60 \%$ & $8 \% / 9 \%$ \\
\hline CSLL & $32 \% / 9 \%$ & $16 \% / 9 \%$ & $8 \% / 15 \%$ \\
\hline IRPJ & $32 \% / 15 \%$ & $16 \% / 15 \%$ & \\
\hline
\end{tabular}

Fonte: Tabela preparada pela autora em 6/2014.

\subsubsection{Lucro Arbitrado}

O Lucro Arbitrado também é calculado pelo percentual de presunção do lucro e também como forma de tributação simplificada, que mantenha vantagem e obrigações das partes envolvidas, quando não se consegui formar seu lucro, quando a contabilidade é imprópria e quando a empresa opta indevidamente pelo lucro presumido.

\subsubsection{Simples Nacional}

O Simples Nacional é uma forma simplificada e unificada de recolhimento de tributos, por meio da aplicação de percentuais favorecidos, incidentes sobre uma única base de cálculo, a receita bruta.

O Simples Nacional, que vige desde $1^{\circ} .07 .2007$, foi instituído pela Lei Complementar $\mathrm{n}^{\circ} 123 / 2006$, e tem como principal objetivo regular o tratamento diferenciado, simplificado e favorecido, aplicável às microempresas e as empresas de pequeno porte, relativo ao IRPJ,IPI,CSL,Cofins, e PisPasep, ICMS e ISS. (SANTOS, BARROS, 2010 p.36).

A opção pelo Simples Nacional, está disponibilizada pelos art. $7^{\circ}$ a $9^{\circ}$ da resolução
4, de 30-05-07, do Comitê Gestor do Simples Nacional.

\subsection{Diferença entre Elisão Fiscal e} Evasão Fiscal

Conforme Oliveira, (2007) estabelecer uma linha divisória entre a elisão fiscal e a evasão é discernir o lícito do ilícito. Esse discernimento nem sempre é fácil, mesmo em tese, porque certos fenômenos estão no liminar entre uma figura e outra. Dependerá da análise das circunstâncias fáticas e jurídicas do caso concreto.

\subsubsection{Elisão Fiscal}

A maneira legal chama-se elisão fiscal ou economia fiscal ou planejamento tributário. Através de um planejamento, evita-se a ocorrência do fato gerador, conseqüentemente não havendo fato gerador não haverá tributo, esse planejamento não caracteriza ilegalidade e sim se usa regras vigentes para sua economia fiscal.

Existem duas maneiras de se fazer uma economia fiscal, primeiro daquela decorrido da própria lei e segunda a que resulta de lacunas e brechas existentes na própria lei.

Elisão fiscal é atividade lícita de busca e identificação de alternativas que, observados os marcos da ordem 
jurídica, levam a menor carga tributária. Essa linguagem requer o manejo competente de duas linguagens: a do direito positivo e a dos negócios; portanto, não se restringe à descoberta de lacunas ou "brechas" existentes na legislação. O planejamento tributário é um exemplo de elisão fiscal. (OLIVEIRA,2007,p. 107)

\subsubsection{Evasão Fiscal}

Conforme Oliveira (2007), evasão ou sonegação fiscal, por outro lado, é resultado de ação ilícita punível com pena restritiva de liberdade e multa. A evasão é o resultado de ação dolosa tendente a impedir ou retardar, total ou parcialmente, o conhecimento por parte da autoridade fazendária da ocorrência do fato gerador da obrigação principal, sua natureza ou circunstâncias materiais, das condições pessoais do contribuinte, suscetíveis de afetar a obrigação tributária ou o crédito tributário correspondente.

A evasão é uma forma ilegal e denomina-se sonegação fiscal. O contribuinte tem duas maneiras de diminuir seus encargos tributários, pode fazê-lo legal ou ilegalmente.

A elisão caracteriza-se por conduta lícita tendente a impedir o surgimento da obrigação tributária evitando a ocorrência do fato gerador, ao passo que a evasão restringe-se a condutas ilícitas, adotadas pelo contribuinte, posteriormente à ocorrência do fato gerador, para evitar, reduzir ou retardar o pagamento de tributo já devido. (Yamashita, 2005 p. 29).

Conforme o Portal Tributário, o planejamento tributário tem como objetivo a economia legal da quantidade de dinheiro a ser entregue ao governo, tendo três tipos de planejamento tributário: “a) evitar a incidência do fato gerador do tributo, b) reduzir o montante do tributo, sua alíquota ou reduzir a base de cálculo do tributo, c) retardar o pagamento do tributo postergando ou adiando o seu pagamento sem a ocorrência de multa.

Conforme a Lei das S/A (6404/76) prevê a obrigatoriedade do planejamento tributário, por partes dos administradores de qualquer companhia, pela interpretação do artigo 153 ("O administrador da companhia deve empregar, no exercício de suas funções, o cuidado e a diligência que todo homem ativo e probo costuma empregar na administração dos seus próprios negócios”).

\subsection{Juros sobre capital próprio}

Conforme Santos e Barros (2010) é uma das formas de distribuir lucros aos acionistas de uma empresa, esse pagamento e tratado como despesa no resultado dessa empresa, nesse caso o investidor terá que pagar IR sobre o capital recebido, essa questão fiscal é exatamente o benefício da companhia, como esse pagamento é contabilizado como despesa da empresa, antes do lucro, a empresa não arca com os tributos, repassando esse benefício para o investidor.

\section{Metodologia}

Considerando o atributo particular da pesquisa e as atividades desenvolvidas através do emprego do processo cientifico, pelo aspecto de quanto aos fins, a pesquisa é descritiva, explicativa e bibliográfica. Descritiva, pois pretende descrever conhecimentos sistematizados relacionado ao planejamento tributário, com a orientação do profissional contábil, explicativa, porque esclarece as razões, de forma genérica, da captação dos conhecimentos correlata à empresa, informação contábil e planejamento tributário e bibliográfico porque para a fundamentação teórica será realizada análise bibliográfica sobre os conceitos do conteúdo e aplicabilidade contábil aliada á necessidade surgida pelos gestores das empresas. 
As pesquisas descritivas têm como objetivo primordial a descrição das características de determinada população de fenômeno ou, então, o estabelecimento de relações entre variáveis, são inúmeros os estúdios que podem ser classificados sob este título e uma de suas características mais significadas está na utilização de técnicas padronizadas de coleta de dados, tais como os questionários e a observação sistemática. (GIL, 2006, p. 42).

Essa pesquisa tem como enfoque a pesquisa qualitativa, tem como fonte $\mathrm{O}$ ambiente dos dados, retratando o maior numero dos elementos existentes.

\subsection{Delimitação da pesquisa}

Esta pesquisa se limita a comparação do planejamento tributário adotado pela empresa prestadora de serviço com a orientação do escritório de contabilidade.

\subsection{População e amostragem}

A população referente a essa pesquisa é a empresa que adotou o planejamento tributário e a amostragem será à analise do planejamento adotado pela empresa com a orientação do escritório de contabilidade.

\subsection{Instrumentos para coleta de} dados

Esta pesquisa tem como coleta de dados, um planejamento tributário adotado pela empresa onde serão analisados os resultados.

\section{Discussao dos resultados}

\subsection{Comparação entre Lucro} Presumido x Lucro Real

Os valores dessas tabelas foram retirados do Balanço Patrimonial e Demonstração do Resultado do Exercício referente à empresa onde foi implantado o planejamento tributário.

A tabela III se refere ao cálculo efetuado para empresa prestadora de serviço tributada pelo lucro presumido.

Tabela III - Cálculo para Tributação Lucro Presumido

\begin{tabular}{|l|c|c|}
\hline Descrição Lucro Presumido & \multicolumn{1}{|l|}{ Valor } & Cálculo Imposto \\
\hline Receita Trimestral & $327.990,04$ & $327.990,04$ \\
\hline Lucros Recebido & $1.120 .854,40$ & Distribuir \\
\hline IRRF s/JCP a compensar & $49.198,51$ & Recuperar na PF \\
\hline ( - ) Pis s/JCP ( 0,65\%) & & $(2.131,93)$ \\
\hline ( - ) Cofins s/JCP( 3,00\% ) & & $(9.839,70)$ \\
\hline ( - ) CSLL ( 32\% / 9\% ) & & $(9.446,11)$ \\
\hline ( - ) IRPJ ( 32\% / 15\%) & & $(15.743,52)$ \\
\hline ( - ) Acicional IRPJ ( 10\% ) & $327.990,04$ & \\
\hline ( - ) Desp. Juros s/JCP & & \\
\hline
\end{tabular}

Fonte: Tabela preparada pela autora em 6/2014. 
Nesse cenário, verificou que no lucro presumido houve a cobrança de PIS, COFINS, CSLL, e IRPJ, pela sua presunção da receita total da empresa, no período de apuração, verificou que houve uma maior carga tributária a ser paga pela empresa.

Tabela IV - Cálculo para Tributação Lucro Real

\begin{tabular}{|l|c|c|}
\hline Descrição Lucro Real & Valor & Cálculo Imposto \\
\hline Receita Trimestral & $327.990,04$ & $327.990,04$ \\
\hline Lucros Recebido & $1.120 .854,40$ & Distribuir \\
\hline IRRF s/JCP a compensar & $49.198,51$ & Recuperar na PF \\
\hline ( - ) Pis s/JCP ( 1,65\%) & & $(24.411,83)$ \\
\hline ( - ) Cofins s/JCP( 7,60\% ) & & \\
\hline ( - ) CSLL ( 32\% / 9\% ) & & \\
\hline ( - ) IRPJ ( 32\% / 15\%) & & $(327.990,04)$ \\
\hline ( - ) Acicional IRPJ ( 10\% ) & $327.990,04$ & \\
\hline ( - ) Desp. Juros s/JCP & & \\
\hline
\end{tabular}

Fonte: Tabela preparada pela autora em 6/2014.

Nesse cenário, constatou que no lucro real houve a cobrança de PIS e COFINS apenas, pois nesse caso a despesa com juros s/JCP é exatamente o valor de sua receita, portanto não havendo lucro e sim um prejuízo, a lógica é que o recebimento de JCP sempre de prejuízo e como esse cenário é tributado pelo lucro real não haverá cobrança de IRPJ e CSLL, havendo uma carga tributária menor a ser paga pela empresa.
A tabela IV se refere ao cálculo efetuado para empresa prestadora de serviço tributada pelo lucro real. 
Tabela V - Resultado Lucro Presumido x Lucro Real

\begin{tabular}{|l|c|c|}
\hline Tributação & Lucro Presumido & Lucro Real \\
\hline Receitas Tributavel & $327.990,04$ & $327.990,04$ \\
\hline Impostos & $(41.656,94)$ & $(30.339,07)$ \\
\hline Valor Líquido & $286.333,10$ & $297.650,97$ \\
\hline
\end{tabular}

Fonte: Tabela preparada pela autora em 6/2014.

\section{Conclusão}

Nesse cenário, tem-se que a tributação com base no lucro real se revela vantajosa por economia fiscal no âmbito do IRPJ e da CSLL.

Isso decorre do fato de que os juros sobre capital próprio são tributados em ambos os regimes (lucro real ou presumido). Mas, no lucro real a distribuição "programada" de juros sobre capital próprio aos sócios da empresa tem o condão de anular a receita de tais juros recebidos da coligada. No lucro presumido, contudo, isto não seria possível, porque a receita dos juros seria integralmente tributada sem possibilidade de dedução dos juros pagos.

Veja-se que isto é possível porque a legislação de regência faculta o cálculo dos juros sobre o capital próprio e seu pagamento limitado ao valor que a empresa queira pagar aos sócios - ou seja, não impõe o pagamento da totalidade; apenas restringe (no lucro real) o máximo dedutível. E, no caso prático em análise, o montante do Patrimônio Líquido da investidora possibilita um volume de juros que anula aquele recebido

Nesse processo podemos concluir com base nos cálculos demonstrada, que na tributação pelo lucro real se tornou mais vantajosa havendo uma elisão fiscal, pois ocorreu uma economia fiscal, devido à empresa ser tributada pelo lucro real e não houve evasão fiscal, pois todos os procedimentos foram feitos de acordo com a legislação.

O impacto nos resultados entre lucro presumido e lucro real aplicado em uma empresa do ramo de atividade prestadora de serviço é que no lucro presumido seu valor líquido ou lucro líquido foi de $87,29 \%$ e no lucro real seu lucro líquido foi de 90,75\% sobre a receita.

Essa pesquisa se limita apenas a empresas prestadoras de serviço tributadas pelo lucro presumido e lucro real focada no imposto de renda e contribuição social, podendo deixar como sugestão para futuras pesquisas, outras verticais de negócios, como comércio e indústria e não apenas empresas que tenham apenas receita de juros sobre capital próprio.

\section{Referências Bibliográficas}

1. ALBERTÃO, Sebastião Edmar. ERP: sistema de gestão empresarial: metodologia para avaliação,seleção e implantação para pequenas e médias empresas. 2. ed. rev. e ampl. São Paulo: Iglu, 2005.

2. ANDRADE FILHO, Edmar Oliveira.

Direito Penal Tributário. Crimes contra a Ordem Tributária e contra a Previdência Social. São Paulo: Atlas, 2007.p.107. 
3. BORGES, Humberto Bonavides. Planejamento tributário: IPI, ICMS, ISS e IR. 9. ed., rev. e ampl. São Paulo: Atlas, 2008.

4. BRASIL: Lei n.9.718/98 \ $1^{\circ}$ do art. 13

5. BRASIL: Lei n. 9.430/96 art. 26\3

6. CASTARDO, Hamilton Fernando. Processo tributário administrativo: doutrina, jurisprudência, legislação. 5. ed. rev. e ampl. São Paulo: IOB, 2011. 637 p. ISBN 9788537910337.

7. CFC - Conselho Federal Contabilidade Resolução n.560. Dispõe sobre as prerrogativas profissionais.

8. CTN - Código Tributário Nacional art.3/1966

9. FABRETTI, Láudio Camargo. Prática tributária da micro e pequena empresa: legislações tributária e empresarial, Lei do simples, tributação da média empresa. 5. ed. rev. e atual. com o novo Código Civil e a. São Paulo: Atlas, 2003

10. FERREIRA, Victor Cláudio Paradela et al. Modelos de gestão. 2. ed. Rio de Janeiro: FGV Editora, 2006.

11. GIL, Antonio de Loureiro; BIANCOLINO, César Augusto; BORGES, Tiago Nascimento. Sistemas de informações contábeis: uma abordagem gerencial . São Paulo: Saraiva, 2010.
12. GIL, Antonio Carlos. Metodos e tecnicas de pesquisa social. 5ed. São Paulo: Atlas, 1999. 207 p. ISBN 8522422702.

13. HIGUCHI, Hiromi; HIGUCHI, Fábio Hiroshi; HIGUCHI, Celso H. Imposto de renda das empresas: interpretação e prática. 36. ed. São Paulo: IR Publicações, 2011.

14. MARION, José Carlos,. Contabilidade básica. 8. ed. São Paulo: Atlas, 2006. 257 p. ISBN 8522445281

15. LISBOA, Lázaro Plácido. Ética geral e profissional em contabilidade. 2. ed. São Paulo: Atlas, 1997. 174 p. ISBN 8522417997. 16. MARION, José Carlos,. Contabilidade básica. 8. ed. São Paulo: Atlas, 2006.

17 .OLIVEIRA, Djalma de Pinho Rebouças de. Planejamento estratégico: conceitos, metodologia, práticas. 25. ed. São Paulo: Atlas, 2008. 331 p. ISBN 8522451451.

18. SANTOS, Cleônimo dos.; BARROS, Sidney Ferro. Imposto de renda pessoa jurídica para contadores: inclui Simples Nacional, CSL, PIS/Pasep e Cofins. São Paulo: IOB Thomson, 2010.

19. TEMAS relevantes do direito tributário e de contabilidade. São Paulo: Ônixjur, 2011. 286 p. ISBN 9788564261044. ( AUTORES: Andréia Lemos Lopes/Claudia Agostinha Santos Souza/ Diogenis Bertolino Brotas/ Giselaine Borges Venet/ Leônio Araujo dos Santos Júnior) 
20. YAMASHITA, Douglas. Elisão e evasão de tributos: planejamento tributário: limites à luz do abuso do direito e da fraude à lei. São Paulo: Lex, 2005. 